\title{
DOORLOPENDE AGENDA
}

\section{I4-I 5 DECEMBER I 979}

50-Jarig bestaan Nederlandse Vereniging van

Ziekenhuisapothekers, met op I5 december een symposium over 'The serum concentration of drugs'.

Medisch Centrum Slotervaart, Amsterdam.

Inlichtingen: Drs. F. А. воом, Slotervaartziekenhuis, Louwesweg 6, 1066 EC Amsterdam, tel.nr. (020) 5124480.

I O-I I JANUARI I 980

Symposium Hulpstoffen.

Academiegebouw, Groningen.

Thema: Voor- en nadelen van het gebruik van hulpstoffen in levensmiddelen, farmaceutische produkten en andere waren.

Inlichtingen: Mr. A. F. STROINK, Martinikerkhof 32, Groningen, tel.nr. (050) 264824.

\section{FEBRUARI I 980}

Jongerendag Farmacologie.

Rudolf Magnus Instituut voor Farmacologie, Vondellaan 6, Utrecht.

Inlichtingen: Dr. P. B. M. W. M. TIMMERMANS, Laboratorium voor Farmacie, Plantage Muidergracht 24, Ior8 TV Amsterdam, tel.nr. (020) $5222219 / 2234$.
I 4 MAART I 980

Symposium Pijn en Pijnbestrijding. Jaarbeurs Congrescentrum Utrecht. Inlichtingen: MSD/Chibret, afdeling Externe Betrekkingen, Waarderweg 39, Postbus 58I, 2003 PC Haarlem, tel.nr. (023) 319330, toestel 2260.

\section{5 MAART I 980}

Decubitus symposium.

Erasmus Universiteit, Rotterdam.

Inlichtingen: Stichting TGo, Postbus I99, 9200 AD Drachten, tel.nr. (05126) 2727.

\section{MAART I 980}

Medisch Informatica Congres 1980 .

Collegezalen Medische Faculteit Erasmus Universiteit, Rotterdam.

Inlichtingen: Ziekenhuis-Computercentrum Stedendriehoek, Sutton 15,7327 AB Apeldoorn, tel.nr. (055) 230733.

I 4-I 8 APRIL I 980

Postgraduate School on Aspects of Toxicological Testing Methods.

University of London.

Inlichtingen: The Department of Pharmacy, Chelsea College, University of London, Manresa Road, London sw3 6LX.

\section{PERSONALIA}

JUBILEA

5o jaar apotheker, I9 december I979: de dames J. E. M. TEN DIJK te. Oegstgeest en J. E. HAGENZIEKER-RUSTING te Leidschendam en de heer Prof. Dr. P. SORGDRager te Huis ter Heide (receptie zaterdag 15 december 1979 I6.00-20.00 uur).

40 jaar apotheker, 2I december I979: Mevr. A. E. HAVERKAMP-VAN TEMMEN te Malaga, Spanje.

25 jaar apotheker, 18 december I979: de heer W. J. VAN DER WOLF te Barneveld.

\section{APOTHEKERSEXAMEN}

Leiden, 22 oktober 1979: de dames A. A. DEKKERS-STOFBERG, T. VAN DER MEIJ en C. M. DE ROOS-HUISMAN en de heren J. A. DE JONG en J. G. TIMMER.

Utrecht, 24 oktober 1979: de heren M. VAN ARNHEM, 'T. N. M. HEBINCK, A. VAN KEMPEN en G. J. KLEIN NULENT.

\section{DOCTORAALEXAMEN}

Amsterdam, 7 november I979: Mevr. J. J. M. HAVERMAN en de heer R. F. L. BUENTING. 